\title{
The Experience and Enlightenment of the Integration of Rural Industries from France and Japan
}

\author{
Jie Zhu \\ The Research and Development Centre \\ Fuzhou University of International Studies and Trade \\ Changle, China \\ 285889359@qq.com
}

\author{
Nan Lin \\ The Department of Finance \\ Fuzhou University of International Studies and Trade \\ Changle, China \\ nanlin36@126.com
}

\begin{abstract}
French rural tourism and Japanese "sixth industrialization" have positive effects in industrial chain extending, farmers' income increasing, and agricultural economic developing. The integration of indus tries in rural China has not been going well. Therefore, the summary of the background, characteristics, and policy supports about the integration of industries in rural area of France and Japan has been meaningful to promote the development of the integration of the three industries in rural China.
\end{abstract}

Keywords-France; Japan; rural industries; integration of development

\section{INTRODUCTION}

The central first document in 2015 proposed a new concept about the integration and development of industries in rural areas. In 2017, it has been pointed out that the optimizing of industrial system must focus on promoting in the deep integration of the three industries, including agriculture, industry and service sector. The central first document in 2015 clearly put forward to develop the new industries and expand the value chain of the agricultural industry.

The integrated development of the primary, secondary, and tertiary industries in rural areas is an important approach to broaden the channels for farmers to increase income and build a modern agricultural industrial system [1]. It is also an inevitable requirement to accelerate the transformation of agricultural development methods and explore the agricultural modernization route of Chinese characteristics.

The Promoting about the integration of the industries in rural areas is a major step to adjust to the economic and social developments in "new normal" [2]. The transformation of agricultural development methods will be accelerated and innovated in the integration. Japanese "sixth industrializations" and French rural tourism have made the contributions to the integration of local agriculture, secondary and tertiary industries in a certain extent [3]. They have also played an important role in the industrial chain extending, farmers' income increasing and rural prosperity promoting.

As the world's largest tourist destination, France's development experience in integration of industries is worth learning. In the meantime, there are many similarities in the geographical and rural resource endowments about China and Japan, which both belong East Asia.

Therefore, the experience of industrial integration from France and Japan has been meaningful to promote the integration and development of China's rural $\mathrm{s}$ industries integration. The summary will be helpful to solve the current problems faced by Chinese farmers, such as the backward management concepts of farmer households, the similarity of tourism services and the imperfect marketing network.

\section{FRENCH RURAL TOURISM}

France is the world's largest tourist destination. Its rural tourism has developed rapidly in recent years to become the second largest tourist product in France. In the 1970s, France began to develop rural tourism. It has formed a comprehensive management model and system of industrial standards and norms for decades. French rural tourism has not caused a negative impact on agricultural development. On the contrary, the agriculture began to be flourishing and productions were highly concentrated. Rural tourism have promoted direct marketing of agricultural products, protected cultural heritage, and adjusted agricultural income seasonally. It has played an important role to solve the survival problems of the farm and boosted the sustainable development of the economy, society, and culture.

\section{A. Background of French Rural Tourism}

France began the process of urbanization process after the Second World War which makes substantial rural residents to flock to cities. The problem of population imbalance between urban and rural populations has become more severe. It led to the labor shortage and aging of the population in rural areas of France, which impeded the sustainable development of agriculture. The French government began to implement "territorial management" to solve the problem, which means the land was concentrated to become industrialized operations. In the meanwhile, the "rural tourism" was proposed to increase the farmers' income. Moreover, France's vacation system led to the growth of short-distance travel which called "weekend tours". And rural tourism became the priority selection for 
short-distance travel, which promoted the further prosperity and development of rural tourism in France.

\section{B. Maintaining the Integrity of the Specifications}

\section{1) Native Specialties}

The Reception of Agriculture and Tourism which is formed by the Permanent Assembly of Agricultural Chambers in France have formulated strict regulations about rural tourism management to promote the direct marketing and specialization of local agricultural products. More specifically, the farms which to offer food and beverage services must use local agricultural products and native cooking methods. In addition, the appearance of the farms must comply with local customs, and tableware and stoneware must be made by representative materials. These regulations have kept the authenticity and uniqueness of rural areas to highlight the characteristics of the farms and avoid homogeneous competition.

\section{2) Efficient Industry Self-regulation}

There is a long history about the cooperation between the French government and industry associations in rural tourism which has started since the beginning of rural tourism. The association formulates industry's rules, regimes and quality standards within the scope of government policies to achieve industry self-regulation. The Agricultural Chambers is a semiofficial public professional association. It is an important communication approach between French government and the farmers. It can not only help the government to provide guidance and training to farmers, but also be a "mouthpiece" for the farmers to negotiate with government. The Permanent Assembly of Agricultural Chambers (APCA) which established in 1935 supervised the policies of the French Ministry of Agriculture to protect farmers' interests. Its subordinate agencies offer farmers a series of services including legal consulting, marketing consulting and training guidance. The industry associations have strongly promoted the standardization and standardization of rural tourism in France.

\section{3) The Advanced Marketing System}

The completed marketing system has been established in French rural tourism. The potential customers who are setting in the surrounding provinces, domestic big cities and major cities in neighboring countries would be promoted about local tourism products. The promotional channels which included website, newspaper, magazines and cooperation with travel agencies could attract more customers. On the other hand, the communications with the guests have been attention to retain the guests through membership cards, emails, and high-quality services. In addition, the "Welcome to the Rural" organization network which designed by the APCA has become a marketing network platform to connect main farms in major regions.

\section{Maintaining the Integrity of the Specifications}

French rural tourism has always been under the regulation of the government, and the main body of French rural tourism is all agricultural developers and rural residents. The government has formulated policies and general guidelines about the development of rural tourism. The industry associations have also been guided to formulate industry norms, collect data and report the statistical analysis of data. In recent years, the government's management functions have got receded, but the supervisory functions have been reinforced.

\section{1) The Support of Legal and Regulatory Support}

The Malraux Act promulgated by French government in 1962 enacts the decree to protect historic blocks, which established a new concept for the protection of old buildings. The traditional buildings can attract more visitors and promotes the development of rural tourism. In 1974, the "Quality Charter" was promulgated to structure strict regulations and standards for the quality of homestay, which included quality of services and the surrounding environment. In addition, the organization of "French family farmhouse" has established strict standards to rate the homestays to provide a reference for the selection of tourists. The French labor law which was revised in 1982 stipulated that all normal workers had 30 days as the Paid annual vacation, which have been helpful to encourage the individuals' travel. The type of law obviously promoted the demands increasing of rural tourism.

\section{2) The Financial Support from Government}

To promote the development of rural tourism, the French government has established relevant preferential taxation policy and financial subsidies for rural tourism operators. In 1955, the French government launched the plan to provide financial support for the farms to promote the maintenance and repairs of traditional-style dwellings. The eligible farmhouses could get government's financial subsidies which accounts for the $10 \%$ to $30 \%$ of the charge. Moreover, the Value-added tax about food in France is only 5.5\% and the occupational taxes on hotels and restaurants are eliminated. In addition, the French government allocated 53 million euros to build highways for rural tourist attractions from 2000 to 2006. the protection and development of tourism resources have been as an important function of the country.

\section{III. "The SIXTH-INDUSTRIALIZATION" IN JAPAN}

In the 1990s, the concept of "sixth industries" are proposed by Japanese scholar which means "six industries= primary industry+ secondary industry+ third industry". The interaction between the three industries was coupled and developed to form a full agricultural industry chain through the integrated development of agricultural production, processing, sales and services which could extend its economic value chain. "The sixth-industrialization for agriculture" aims to allow farmers to share more benefits from agricultural industrial chain extension and agricultural structure transformation by promoting the integration of three industries in rural areas. In recent years, the developments of Japanese agriculture about "sixth industrialization" have been in a good state. The great achievements have been made in improving the competitiveness of products, expanding the functions of agriculture, and increasing the income of farmers.

\section{A. The Background of Japan's "Sixth Industrialization"}

In the 1990s, the processing, circulation and consumption of Japanese agricultural products were all carried out outside of rural areas. As a result, farmers were unable to share the valueadded benefits of the extension of the agricultural industry chain. The rural labor forces were seriously lost because mass 
rural population migrated to cities. The aging problem of the agricultural population and the over-reduction of agriculture industry are increasingly serious. The income of Japanese farmers continued to decline in the 21st century. The wholesale markets and supermarkets have captured more profits from the agriculture productions to squeeze the rural income and employment rate.

The outflow of rural population has led to extremely uneven development between urban and rural areas. And the pressures of import in agricultural products has been increasing which caused by trade liberalization. The Japanese government has gradually accepted the development concept of "sixth Industrialization” under this background. In addition, people have begun to pay more attention to healthy diets as the nation's overall income level has increased. Japanese agricultural policy has also focused the provision of quality and healthy agricultural products for consumers to promote the communications between agricultural producers and consumers The integrations of production and sales could be realized by the communications.

\section{B. The Characteristics of Japan's "Sixth Industrialization"}

1) The Deep Cooperation between Agriculture, Industry and Business

The Japanese government aims to promote agriculture by the supports of industry and commerce based on relevant regimes. The small and medium-sized enterprises can take advantage of their conditions of manufacture to process agriculture products to enhance cooperation and enhance overall value of products.

The purpose of Japanese government is to guide the producers of agriculture to become the main business entities, rather than the merging of agricultural producers by industrial and commercial capital. Therefore, the proportion of capital in industry and commerce should not exceed $49 \%$ to ensure farmers can share the dividends from the development of industrial integration and increase their income.

\section{2) Local Consumption of Local Products}

The core of the "sixth industrialization" of Japanese agriculture is to come true local consumption of local agricultural products. The first key point is that local products have been used as raw materials rather than imported products, and the second point is to handle products in the local processing factories. The procedures of processing, circulation, and consumption are internalized in local areas.

\section{3) Technological Innovation and Brand Promotion}

The agricultural department of government has formulated the "research plan about development of agriculture, forestry and fisheries" to encourage the research and development of agricultural innovation technologies. The three key points which included the protection of intellectual property rights, the development of bio-energy, and the usage of renewable energy in rural areas have been focused. Japan's central government has established a scientific management system to promote the building of agricultural products brand. The tourism department and rural areas have jointly created the tourism brands, and, promoted the development of industrial integration through the development of agricultural branding which have increased the benefits of farmers' income.

\section{The Supported Policy from Japanese Government}

After the 1960s, the Japanese government has continued to increase investment in rural infrastructure construction to provide basic environment for "sixth industrializations". A series of financial subsidies including fixed-rate subsidies and proportional subsidies have been implemented by Japanese government. For example, the subsidy of half cost in the equipment purchase and construction expenses for processing and selling agricultural products would be given to the farms. Moreover, the term of interest-free agricultural reform loans extending and the maximum amount of loans increasing have been executed to reduce the rural fiscal pressure.

\section{ThE ANALYsis AND ENLIGHTENMENTS FROM THE ACTIONS OF FRANCE AND JAPAN}

From the development experience of France and Japan, the promotion of the development in the integration of industries should combine local actual conditions and take advantages of the located areas. The government should respect the wishes of farmers and coordinate the development with the multifunction of agriculture.

\section{A. Government's Supports from Fiscal Policies and Planning Management}

Both France and Japan have formulated corresponding plans to guide the integration of rural industries in a strategic perspective. The forms of fiscal incentives, subsidies and interest-free loans are implemented to stimulate the development of various business entities [4]. The corresponding laws, regulations and various policies are formulated by the central government to guarantee the development of rural industrial integration. In addition, local policies are formulated to cooperate located conditions to guide the autonomous development of all rural areas.

China's central document has emphasized the requirement about development of the rural industries, and integration of development is an effective way to solve the "three rural issues". Local governments should effectively implement the central government policy to formulate development plans that suit the local conditions [5]. At present some Chinese rural areas are underdeveloped. The government must increase investment in basic infrastructure construction in rural areas, standardize agricultural financial subsidies and simplify mortgage procedures.

\section{B. The Highlights of Local Characteristics}

France has stipulated strict management regulations to avoid vicious competition' caused by similar products. It is necessary to guide the development of integrated rural industries to reflect the history, culture and national characteristics of the region. It also was emphasized that restaurants must use local agricultural products and cooking methods to promote "direct sales" of agricultural products, which is consistent with the purpose of "sixth industrialization" in Japan that emphasizes "local consumption of local products". 
The development of Chinese rural industry integration has appeared serious homogenous competition, product similarities, and lack of features [6]. The countless practitioners have simulated the successful tourism product regardless of actual conditions. It should be considered seriously about the key factors included positions, highlighting features, brand and the industrial chain extending.

\section{The Dominant Position of Farmers}

The dominant position of French rural tourism is "all agricultural developers and rural residents", while Japan requires that the share of industrial and commercial capital must not exceed $49 \%$ to protect the interests of farmers. Hence, farmers can share the extended dividends of the agricultural industry chain and raise the income level.

Chinese farmers could be encouraged to truly participate in the development of the integration of industries in rural areas. It is necessary to improve the interest linkage mechanism, improve order agriculture and promote joint-stock system. The link mechanism encourages the entry of industrial and commercial capital uses the advantages in capital, technology, and management concepts to promote the participation of agricultural producers in the development of rural industrial integration.

\section{The Establishment of an Industry Self-regulation System}

Both France and Japan have formulated standards for the quality of agricultural products and service quality in a detailed manner to guide the standard development. In China, it is necessary to implement the establishment of an industry exchange platform and to play the role of an exchange link. Detailed formulation of industry standards such as hotels, restaurants, entertainment can provide actions' means for farmers in related to laws and policies.

\section{REFERENCES}

[1] G.B. Liu and L.N. Wang, "Experience and Enlightenment of the Development of Rural Industrial Integration in Japan and South Korea,” Jou. Har. Uni. Com, vol.151 pp. 46-52, June 2016.

[2] W. Liu and J. Wang, "The Enlightenment to China of E-government Application in Rural Areas from Japan, South Korea and India,” IFIP International Federation for Information Processing, vol.258 pp. 35-42, 2007.

[3] J.W. Yuan and X. Dong, "The Narrowing Experience \& Enlightenment of the Urban and Rural Residents Income Gap in East Asia,” Journal of Zhengzhou Institute of Aeronautical Industry Management, vol.29 pp. 106-108, Feb 2011.

[4] H.C. Luo and R.Z. Liu, "The Experience and Enlightenment of Foreign Spatial Planning of Urban-rural Integration,” World Regional Studies, vol.23 pp. 69-75, June 2014.

[5] Z.H. Han “Experience and Enlightenment of the Synchronous Development of Japanese Rural Industrialization,Urbanization and Agricultural Modernization," Journal of Minzu University of China(Philosophy and Social Sciences Edition), vol.39 pp. 23-28, Jan 2012.

[6] K.H. Du and Q.S. W, “Japan and India's Experience and Enlightenment of Financial Support to Rural Construction,” Japanese Research, vol.26 pp. 24-27, Feb 2012. 